\title{
Các nhân tố tác động đến hợp tác lâu dài của nhà bán lẻ với nhà cung cấp
}

\section{Factors impacting long-term business relationship between suppliers and retailers}

\author{
Phạm Thị Hồng Diệu ${ }^{1}$, Nguyễn Văn Phương ${ }^{2 *}$ \\ ${ }^{1}$ Trường Đại học Mở Thành Phố Hồ Chí Minh, Việt Nam \\ ${ }^{2}$ Trường Đại học Quốc tế, Đại học Quốc gia Thành phố Hồ Chí Minh, Việt Nam \\ "Tác giả liên hệ, Email: nvphuong @ hcmiu.edu.vn
}

\section{THÔNG TIN}

DOI: $10.46223 / \mathrm{HCMCOUJS.}$

econ.vi.13.3.506.2018

Ngày nhận: 08/10/2018

Ngày nhận lại: 27/10/2018

Duyệt đăng: 31/10/2018

Tù khóa:

chuỗi cung ứng; nhà bán lẻ, nhà cung cấp, quan hệ hợp tác lâu dài, siêu thị

Keywords:

long-term business relationship, retailer, supermarket, supplier, supply chain

Sử dụng dữ liệu thu thập từ các siêu thị tại Thành phố Hồ Chí Minh, nghiên cứu này đánh giá dịch vụ cung ứng dưới góc nhìn của các nhà bán lẻ. Nghiên cứu dẫn đến cái nhìn rõ hơn các nhà bán lẻ đánh giá nhà cung cấp mang lại các chiến lược quan trọng và hoạt động giá trị đến cho các nhà bán lẻ như thế nào. Kết quả của nghiên cứu cho thấy một mối quan hệ hợp tác lâu dài được xây dựng dựa trên sự tin tưởng và cam kết từ các nhà bán lẻ. Khi nhà bán lẻ tin rằng các nhà cung cấp là trung thực, thiết tha và quan tâm đến kinh doanh của họ, họ sẽ cam kết hướng tới mối quan hệ kinh doanh lâu dài.

ABSTRACT
Using data collected from Ho Chi Minh City supermarkets,
this research evaluates supply chain services from the eyes of
retailers. The study gives us a closer look at how retailers view
suppliers in providing them with important strategic and
operational values. The results indicate that a long-term
commercial partnership is set up based on trust and commitment
from retailers. When retailers believe that a provider is honest,
enthusiastic and care for their business, they are ready to commit
a mutual long-term business relationship.

\section{ABSTRACT}


tập trung vào hai thành phố lớn là Thành phố Hồ Chí Minh (TP.HCM) và Hà Nội. Qua đó nhận thấy, bức tranh thị trường bán lẻ tại Việt Nam rất sinh động khi có nhiều doanh nghiệp bán lẻ Việt Nam và nước ngoài tham gia. Dự báo trong tương lai sẽ xảy ra một sự cạnh tranh khốc liệt giữa các doanh nghiệp trong thị trường bán lẻ đầy tiềm năng này, đặc biệt đối với các doanh nghiệp bán lẻ Việt Nam nói chung và TP.HCM nói riêng. Để các nhà bán lẻ trong nước gia tăng khả năng cạnh tranh trước sức ép từ những đối thủ cạnh tranh nước ngoài, một trong những vấn đề sống còn là phải phát triển mạnh hệ thống bán lẻ. Hoạt động quản trị mua hàng và quản trị quan hệ nhà cung cấp là hoạt động đầu vào của bất kỳ nhà bán lẻ nào và có ảnh hưởng lớn đến cấu trúc chi phí của doanh nghiệp, liên quan đến việc kiểm soát thời gian giao hàng, tỷ lệ hao hụt, chất lượng sản phẩm cũng như phản ảnh khả năng đáp ứng sản phẩm đến tay người tiêu dùng. Các nhà bán lẻ, nhiều giám đốc điều hành của các công ty sản xuất quan tâm đến việc xây dựng một mối quan hệ hiệu quả với nhà cung cấp hậu cần để đảm bảo việc thực hiện chuỗi cung ứng chất lượng tốt nhất có thể (Rafiq \& Jaafar, 2007; Hsiao, Lin, Wang, Lu, \& Yu, 2010; $\mathrm{Li}, 2011)$.

Bài báo cáo này nghiên cứu ảnh hưởng các yếu tố lợi ích từ mối quan hệ của nhà cung cấp với nhà bán lẻ. Lợi ích mối quan hệ dựa trên giả định rằng cả hai bên - người cung cấp dịch vụ và người thụ hưởng dịch vụ - trong mối quan hệ kinh doanh phải hưởng một lợi ích nào đó khi mối quan hệ này tiếp tục trong dài hạn (Henning-Thurau, Gwinner, \& Gremler, 2002). Khi các nhà bán lẻ cảm nhận được lợi ích mối quan hệ sẽ giúp cả hai bên làm việc dễ dàng và cải thiện hiệu suất (Cannon \& Perreault, 1999; Rokkan, Heide, \& Wathne, 2003). Từ các tài liệu nghiên cứu về mối quan hệ từ giữa những năm 1990 (Bendapudi \& Berry, 1997; Berry, 1995; Gwinner, Gremler, \& Bitner, 1998). Nhà nghiên cứu cho rằng khi các nhà bán lẻ nhận thức được các lợi ích quan hệ sẽ làm cho các đối tác trong chuỗi cung ứng dễ dàng đạt được sự hài lòng và thu lại kết quả thành công.

Đối với nghiên cứu này, lợi ích quan hệ được định nghĩa là những lợi ích về giá trị vật chất và giá trị tinh thần mà các nhà bán lẻ đã nhận được khi hợp tác với các nhà cung cấp. Lợi ích quan hệ có xu hướng kết nối các công ty thông qua các mối liên kết khác nhau của một chuỗi cung ứng với kết quả của mối tương tác chặt chẽ, cam kết lẫn nhau, và thúc đẩy hoạt động mong muốn. Mặc dù cách tiếp cận này đã được công nhận rộng rãi là quan trọng trong các tài liệu (Berry, 1995; Gwinner et al., 1998), tuy nhiên vai trò trung tâm của quan hệ lợi ích trong hoạt động bán lẻ nhận thấy bởi các nhà quản lý thường bị bỏ qua trong nghiên cứu hiện tại. Nghiên cứu hiện tại chỉ mối quan hệ chuỗi cung ứng chủ yếu đã tìm cách để giải thích bản chất của mối quan hệ quá trình chứ không phải là ảnh hưởng của nó trên hiệu suất (Fynes, de Búrca, \& Voss, 2005).

Trong việc xây dựng nền tảng lý thuyết nghiên cứu của chúng tôi, chúng tôi tiếp cận từ hai phương pháp. Khái niệm lợi ích quan hệ từ các tài liệu marketing (Bendapudi \& Berry,1997; Berry, 1995; Gwinner et al., 1998). Khái niệm sự tin tưởng/cam kết và mối quan hệ lâu dài từ cả hai tài liệu marketing và tài liệu trong hoạt động vận hành tổ chức/cung ứng (Benton \& Maloni, 2005; Morgan \& Hunt, 1994; Sargeant, Ford, \& West, 2006). 


\section{Cơ sở lý thuyết}

\subsection{Nhận thức lợi ích của mối quan hệ}

Để tạo dựng và duy trì mối quan hệ lâu dài giữa người cung cấp dịch vụ và khách hàng người thụ hưởng dịch vụ, cả hai bên đều phải được lợi ích nào đó trong mối quan hệ. Trong quan hệ marketing, các nhà cung cấp đã thay đổi từ chỉ tập trung vào việc mua bán cứng nhắc sang xây dựng các mối quan hệ dài lâu, lợi ích mối quan hệ này là lợi ích mà khách hàng nhận được khi hai bên cùng có lợi (Berry, 1995; Hsiao et al., 2010). Loại lợi ích mà các nhà bán lẻ đang tìm kiếm bao gồm giảm chi phí, chất lượng phân phối, các dịch vụ mới và sáng tạo, truyền thông hợp tác (Chiang và cộng sự, 2011; Kumar, 2011; Qureshi, Kumar, \& Kumar, 2007; Shen và cộng sự, 2010; Strassfield ,2010; Trentin, 2010). Do đó mà hoạt động trong chuỗi cung ứng định hướng theo hành vi đã làm cho các nhà cung cấp phải bổ sung thêm các dịch vụ mới và sáng tạo để thu hút các nhà bán lẻ (Strassfield, 2010).

Khi được áp dụng chính xác, các lợi ích liên quan được tạo ra trong chuỗi cung ứng có thể là lợi thế cạnh tranh trong chuỗi cung ứng tổng thể của công ty (Mentzer et al., 2001). Loại lợi ích quan hệ này cho phép các nhà bán lẻ giảm hàng tồn kho và duy trì các dây chuyền chuỗi cung ứng không bị gián đoạn. Có thể định nghĩa tổng quát lợi ích từ mối quan hệ là những lợi ích mà khách hàng nhận được không những đến từ việc sử dụng hay trải nghiệm những sản phẩm và dịch vụ cốt lõi mà là kết quả của việc tạo dựng mối quan hệ lâu dài với nhà cung cấp dịch vụ (Henning-Thurau et al., 2002). Theo nghiên cứu thực nghiệm của Li (2011), cho rằng lợi ích từ mối quan hệ bao gồm ba loại lợi ích quan trọng: lợi ích giá trị gia tăng, lợi ích hợp tác và lợi ích kinh tế.

\subsubsection{Lợi ích giá trị gia tăng}

Lợi ích giá trị gia tăng là một tiến trình tự nhiên trong việc mở rộng kinh doanh, khi mà cùng lúc có nhiều nhà cung cấp cung cấp sản phẩm và dịch vụ cùng loại, để tạo lợi thế cạnh tranh, các nhà cung cấp phải thật sự hiểu nhà bán lẻ của mình và phải có kinh nghiệm khi tham gia vào các thị trường mới (Long $\&$ Nelson, 2010). Dựa vào lịch sử mua bán và sự hiểu biết đối tác của mình, nhà cung cấp có thể dự đoán được thời gian, sản phẩm, dịch vụ, ... cần cung cấp trước khi nhà bán lẻ phát sinh ra nhu cầu. Cung cấp dịch vụ trước khi mua hàng là cách các nhà cung cấp tạo ra giá trị gia tăng cho nhà bán lẻ. Ví dụ, với các công ty trong lĩnh vực hàng tiêu dùng nhanh (FMCG) như Unilever, $\mathrm{P} \& \mathrm{G}$ thông qua phương thức nhà tiếp thị thương mại (trade marketing) thực hiện các hoạt động như phát hàng mẫu, tổ chức sự kiện, khuyến mãi... cùng nhà bán lẻ đem đến sản phẩm cho người tiêu dùng một cách đầy đủ nhất. Thay đổi và sáng tạo từ nhà cung cấp làm cho phương thức tiếp thị quảng cáo trở nên mới mẻ hơn giúp gia tăng giá trị lợi ích.

Một lợi ích giá trị gia tăng khác nữa của nhà cung cấp là cập nhật thông tin và kiến thức về các quy định quy tắc mới, tuân thủ an toàn. Trong nghiên cứu này, lợi ích giá trị gia tăng cũng liên quan đến sự quen thuộc của nhà cung cấp với các doanh nghiệp, các quy tắc an toàn và trách nhiệm tuân thủ. Điều này tạo ra một giá trị lợi ích thật sự cho nhà cung cấp. Ý thức giảm bớt lo lắng, tin cậy được vào người cung cấp, giảm nhận thức về rủi ro và đáp ứng đúng những mong đợi là lợi ích giá trị gia tăng quan trọng mà nhà cung cấp mang lại cho nhà bán lẻ. 
Ngoài ra, Bruning (2019) cho rằng việc chia sẻ thông tin hợp tác tích cực trong chuỗi cung ứng sẽ giúp cho việc quản trị rủi ro được tốt hơn.

\subsubsection{Lợi ích hơp tác}

Một chuỗi cung ứng mạnh hay yếu tùy vào mối liên kết của nó. Quan niệm ở đây là tập trung vào sự hợp tác mạnh mẽ và có hiệu quả. Điểm cơ bản phân biệt quản lý chuỗi cung ứng và quản lý nguồn lực truyền thống là cách phối hợp giữa các đối tác kinh doanh được quản lý như thế nào. Do đó, hợp tác là một vấn đề quan trọng trong quản lý chuỗi cung ứng toàn cầu hiện nay (Li, 2006; Li \& Warfield, 2011; Raweewan \& Ferrell, 2018). Li (2011) chỉ ra rằng cốt lõi của hợp tác là trao đổi thông tin là kết nối các liên kết của một chuỗi cung ứng với nhau. Lợi ích hợp tác khác với lợi ích giá trị gia tăng, hợp tác là tập trung vào chia sẻ thông tin và truyền thông; Trong khi dịch vụ giá trị gia tăng tập trung vào các lợi ích bổ sung cho dịch vụ chính.

Lợi ích của hợp tác trao đổi thông tin có đóng góp vào mối quan hệ hỗ trợ và hợp tác kinh doanh lẫn nhau (Mohr, Fisher, \& Nevin, 1996; Prahinski \& Benton, 2004). Prahinski và Benton (2004) nghiên cứu hành vi quan hệ từ quan điểm của nhà cung cấp và kết luận rằng hợp tác trao đổi thông tin sẽ bổ sung lẫn nhau giữa các nhà bán lẻ và nhà cung cấp và có ảnh hưởng tích cực đến sự hài lòng của nhà bán lẻ. Chia sẻ thông tin và sự liên đới giữa các nhà cung cấp và nhà bán lẻ tạo điều kiện cho dự đoán nhu cầu của nhau, thúc đẩy hợp tác và điều phối. Xu (2011a); Xu (2011b); Li (2006) phát hiện ra rằng sự hợp tác trọn vẹn và chia sẻ thông tin thường xuyên, kịp thời giữa các đối tác thương mại giúp liên kết quá trình cung và cầu, cho phép chuỗi cung ứng đáp ứng kịp thời nhu cầu và lợi ích của người tiêu dùng hơn. Một cuộc khảo sát các nhà sản xuất (Strassfield, 2010) đồng ý rằng một doanh nghiệp mạnh là một doanh nghiệp cùng nhau hợp tác trao đổi thông tin để đảm bảo xuyên suốt tầm nhìn, chiến lược, kế hoạch kinh doanh từ đầu vào cho đến đầu cuối.

\subsubsection{Lợi ích kinh tế}

Mục tiêu của hợp tác chuỗi cung ứng trong nghiên cứu này liên quan đến hỗ trợ lẫn nhau thông qua việc cải thiện truyền thông và chia sẻ thông tin giữa các nhà bán lẻ và nhà cung cấp cho phép các đối tác thương mại xem toàn bộ chuỗi cung ứng từ đầu này đến đầu kia. Lợi ích kinh tế mà các nhà bán lẻ nhận được khi tham gia giao dịch chủ yếu dựa vào tiền tệ. Peterson (1995); Sheth và Parvatiyar (1995) cho rằng lợi ích kinh tế là động lực chính cho việc phát triển mối quan hệ giữa các tổ chức kinh doanh và chuỗi cung ứng. Loại lợi ích kinh tế có thể là những cân nhắc đặc biệt về giá đối với những khách hàng đã phát triển mối quan hệ kinh doanh lâu dài với một nhà cung cấp hoặc có thể được khuyến mãi và tỷ lệ chiết khấu đặc biệt. Các điều khoản thanh toán cũng được coi là những lợi ích quan trọng cho các nhà bán lẻ. Ngoài ra, Luthra, Mangla, Chan, và Venkatesh (2018) cho rằng nếu xây dựng hệ thống thông tin quản lý chuỗi cung cứng hiệu quả không những mang lại lợi ích kinh tế mà còn gia tăng việc cung ứng dịch vụ cho khách hàng tốt hơn và đồng thời hướng tới phát triển kinh doanh bền vững hơn.

\subsection{Kết quả của mối quan hệ}

Bài nghiên cứu hy vọng rằng các lợi ích quan hệ sẽ ảnh hưởng đến các kết quả quan hệ (như lượng bán, vị thế thị trường, và một quy trình cung ứng thuận lợi) dưới cách nhìn của nhà bán lẻ. Lợi ích quan hệ làm định hướng và khung thể chế để hướng dẫn thực hiện. Trong quan 
hệ nhân quả, nó có thể được lập luận một cách hợp lý rằng sự tồn tại của một loạt các lợi ích quan hệ sẽ dẫn đến một kết quả quan hệ tích cực. Thứ nhất, với sự phát triển của lợi ích quan hệ, các nhà bán lẻ và nhà cung cấp sẽ có khả năng tốt hơn để xây dựng kỳ vọng lẫn nhau và tăng cường khả năng thích ứng chung. Thứ hai, khi các sự kiện không lường trước được, nhà cung cấp sẽ giúp các đối tác của mình giải quyết các vấn đề và đạt được các mục tiêu thực hiện (Benton \& Maloni, 2005; Prahinsky, \& Benton, 2004; Abreu, Grinevich, Hughes, Kitson, \& Ternouth, 2008).

Lập luận lợi ích quan hệ cho rằng khi nhận thấy lợi ích mối quan hệ tồn tại, toàn bộ quá trình có thể dự đoán sự phát triển tương lai từ các mối quan hệ hiện tại (Henning-Thurau et al., 2002). Hợp tác trong chuỗi cung ứng khuyến khích việc thích ứng và hiểu biết (Ma, Wang, \& Xu, 2011; Zdravkovic, Magnusson, \& Westjohn, 2011). Với quy tắc như vậy, nó tác động vào việc sử dụng chuyên môn và các nguồn lực từ cả hai nhà bán lẻ và nhà cung cấp để đạt được một vị thế thị trường và kết quả thuận lợi (Davis-Sramek, Mentzer, \& Stank, 2008). Đây là một quá trình lặp đi lặp lại. Trong các tài liệu marketing, càng có nhiều lợi ích được nhận thức, càng có nhiều khả năng rằng mối quan hệ sẽ được coi là thành công và tạo ra sự sẵn sàng để tham gia vào các giao dịch khác với cùng một đối tác (Ganesan, 1994; Ford, 1980). Chắc chắn khi công việc được thực hiện tốt với sự hài lòng của các nhà bán lẻ cùng với cảm giác hợp tác và cùng chung lợi ích, thì mối quan hệ được coi là thành công và tạo ra những kết quả quan trọng.

\subsection{Lòng tin, cam kết, và mối quan hệ kinh doanh lâu dài}

\subsubsection{Lòng tin}

Ở đây một kết quả quan hệ tốt sẽ là nền tảng cho sự phát triển của lòng tin và là cơ sở để cam kết mối quan hệ này trong dài hạn (Morgan \& Hunt, 1994; Morton, Dainty, Burns, Brookes, \& Backhouse, 2006). Tin tưởng được định nghĩa là lòng tin hoặc niềm tin mà qua quá trình làm việc cùng nhau, đối tác tin về sự trung thực, uy tín và lòng tốt của các đối tác khác (Ganesan, 1994; Kumar, Scheer, \& Steenkamp, 1995). Uy tín có nghĩa là trong công việc, đối tác tin và tín nhiệm bên kia có chuyên môn cần thiết để thực hiện nhiệm vụ dự kiến một cách hiệu quả, trong khi lòng tốt là một ý nghĩ người bên kia có ý định và động cơ có thể có lợi cho mối quan hệ (Ganesan, 1994). Các nghiên cứu về mối quan hệ giữa người mua và người cung cấp trong chuỗi cung ứng đã chứng minh mối liên hệ tích cực giữa lòng tin và quan hệ thành công (Benton \& Maloni, 2005) cũng như giữa lòng tin và sự hài lòng với lợi nhuận (Mohr et al., 1996).

\subsubsection{Cam kết}

Mặt khác, cam kết đề cập đến niềm tin của một đối tác tin rằng mối quan hệ đang diễn ra với đối tác khác là rất quan trọng, bảo đảm mọi nỗ lực tối đa để duy trì nó (Moorman, Zaltman, \& Deshpande, 1992). Nghĩa là, cam kết xuất hiện khi cả hai phía (nhà cung cấp và nhà bán lẻ) nhận ra tầm quan trọng của mối quan hệ và sau đó cùng nỗ lực để đảm bảo mối quan hệ này được bền vững (Morgan \& Hunt, 1994). Kết quả cam kết đem lại lợi ích chung cho cả nhà bán lẻ và nhà cung cấp trong mối quan hệ cung ứng. Sau khi xem xét các chức năng của nhà cung cấp, Prahinski và Benton (2004) nhận thấy rằng cam kết có một tác động trực tiếp và tích cực đến hiệu suất. Hơn nữa, cải tiến hiệu suất thường được tìm thấy có liên quan đến cam kết của một công ty đối với mối quan hệ kinh doanh lâu dài. 
Theo Morgan và Hunt (1994), về tầm quan trọng của lòng tin và cam kết trong việc phát triển mối quan hệ lâu dài giữa các tổ chức. Vấn đề là một mối quan hệ thực sự không thể tồn tại mà không có lòng tin và cam kết. Từ quan điểm truyền thống của các nhà quản lý tổ chức vận hành, thì mối quan hệ liên quan đến nhà cung cấp sẽ được đánh giá bởi hiệu quả sản xuất và hiệu quả trong việc giảm thiểu chi phí. Và các nhà bán lẻ hiện đang trở thành nhà quản lý quan hệ đối ngoại và lòng tin, cam kết trở thành những khái niệm quan trọng trong quản lý mối quan hệ.

\subsubsection{Mối quan hệ kinh doanh lâu dài}

Niềm tin có thể làm cho các đối tác trong tương lai có thể mở rộng quan hệ hợp tác, làm cho mối quan hệ với bên thứ ba có trách nhiệm hơn, ổn định và bền vững hơn, sau đó cải thiện mối quan hệ kinh doanh lâu dài. Một khi lòng tin đã được thiết lập, các nhà bán lẻ có thể cam kết giữ mối quan hệ lâu dài với nhà cung cấp. Trong một nghĩa nào đó, lòng trung thành là mối quan hệ lâu dài. Nhìn chung người ta thống nhất rằng các cơ chế quan hệ trong hợp tác chuỗi cung ứng bao gồm các kết quả quan hệ, lòng tin/cam kết và lòng trung thành. Trong nghiên cứu này, nhà nghiên cứu sử dụng "mối quan hệ kinh doanh lâu dài" như một thuật ngữ trung thành của hoạt động. Đề xuất này được hỗ trợ bởi một số nghiên cứu đã công bố. Ví dụ, Stank, Keller, và Daugherty (2003) cho thấy sức mạnh của mối quan hệ giữa hiệu suất hoạt động và sự hài lòng của khách hàng là một yêu cầu về dịch vụ, dẫn đến lòng trung thành của khách hàng.

\subsection{Thiết kế mô hình lý thuyết}

Mặc dù có vô số các khái niệm được thảo luận được chỉ ra trong các tài liệu về xây dựng mối quan hệ trong chuỗi cung ứng và phần lớn chỉ tập trung vào một số điểm. Trong số đó các khái niệm phổ biến nhất là lợi ích, kết quả, sự tin tưởng, cam kết và lòng trung thành. Mô hình lý thuyết được xây dựng trên các luồng nghiên cứu về các lợi ích quan hệ có nguồn gốc từ các tài liệu marketing (Gwinner et al., 1998; Henning-Thurau et al., 2002), kết quả quan hệ, lòng tin/cam kết và mối quan hệ kinh doanh lâu dài trong tài liệu quản lý chuỗi cung ứng (Benton \& Maloni, 2005; Stank et al., 2003; Morton và cộng sự, 2006), nghiên cứu này phát triển một mô hình lợi ích quan hệ trong nội dung mối quan hệ của nhà cung cấp và nhà bán lẻ (Hình 2). Mối quan hệ giữa nhà bán lẻ và nhà cung cấp được tạo ra khi nhà bán lẻ nhận thức lợi ích mối quan hệ (lợi î́ch giá trị gia tăng, lợi ích hợp tác và lợi ích kinh tế) mà nhà cung cấp mang lại cho nhà bán lẻ. Kết quả quan hệ này của nhà cung cấp có ảnh hưởng đến sự tin tưởng và cam kết của nhà bán lẻ. Ngoài ra lòng tin của nhà bán lẻ cũng sẽ tác động đến sự cam kết mà nhà bán lẻ dành cho nhà cung cấp của họ. Khi mối quan hệ giữa nhà bán lẻ và nhà cung cấp được củng cố thông qua lòng tin và cam kết, dẫn đến mối quan hệ kinh doanh lâu dài cho cả hai bên.

Qua những mô tả trên đây, sự tương quan giữa các khái niệm nghiên cứu được mô hình hóa trong mô hình lý thuyết (Hình 1).

Hình 1 , Nhận thức lợi ích mối quan hệ và kết quả quan hệ của nhà bán lẻ là tiền thân của niềm tin/cam kết và mối quan hệ kinh doanh lâu dài. Dựa trên các tài liệu nghiên cứu và thảo luận của chúng tôi với các nhà quản lý doanh nghiệp, cho thấy khả năng có sự tương tác giữa các khái niệm này. Kỳ vọng này dẫn đến giả thuyết đầu tiên của chúng tôi. Chúng tôi, dự đoán rằng, nhận thức của nhà bán lẻ về lợi ích giá trị gia tăng, lợi ích hợp tác và lợi ích kinh tế mà nhà cung cấp mang lại sẽ góp phần vào kết quả quan hệ. 
H1: Lọi ích giá trị gia tăng ảnh hương tích cục đến kết quả quan hệ

H2: Các lợi ích cộng tác ảnh hương tích cực đến kết quả quan hệ

H3: Lợi ích kinh tế tích cực ảnh hưởng đến kết quả quan hệ

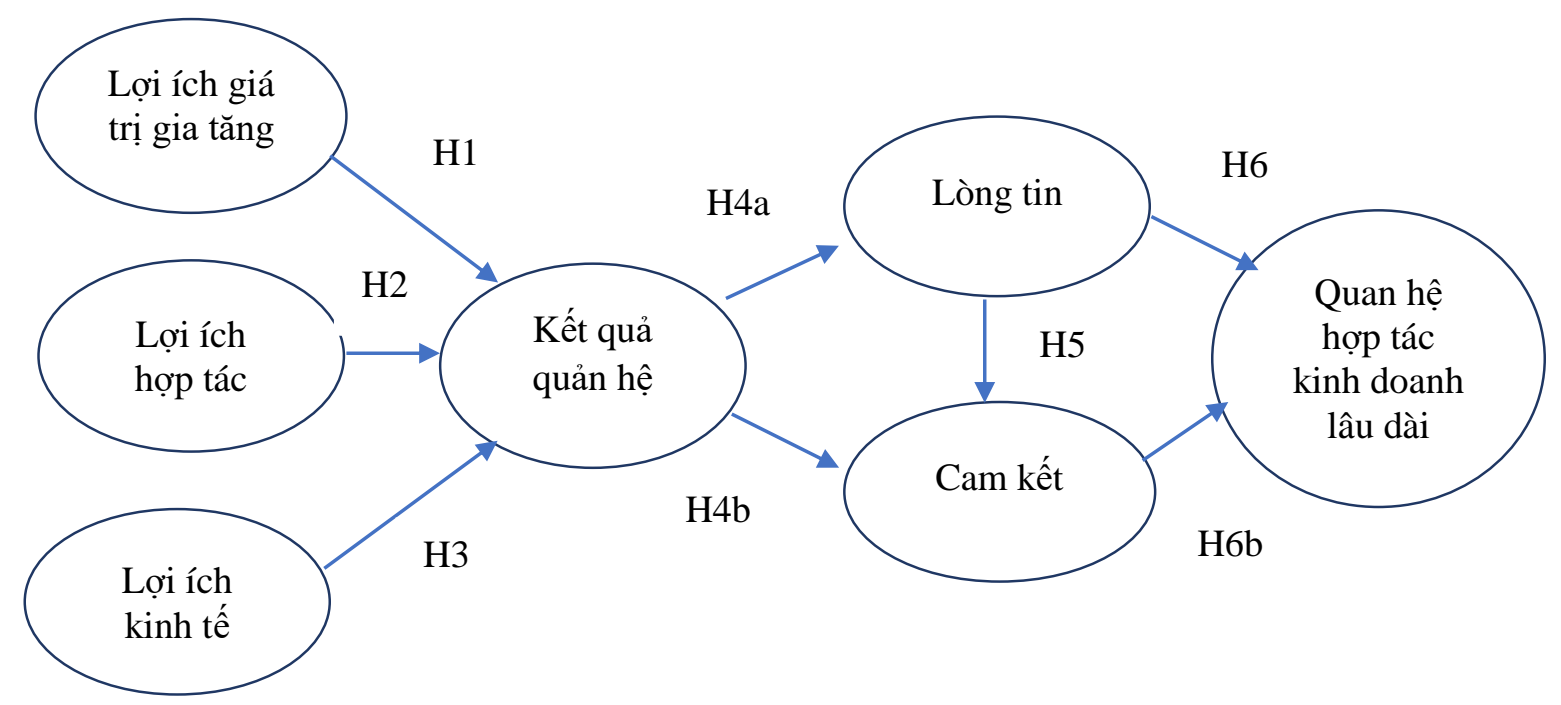

Hình 1. Mô hình nghiên cứu đề xuất

Những nghiên cứu thực nghiệm về quản trị mối quan hệ trong cung ứng đã cho thấy có mối quan hệ nhân quả giữa các lợi ích quan hệ, niềm tin/cam kết và mối quan hệ kinh doanh lâu dài (Davis-Sramek et al., 2008; Daugherty, Stank, \& Ellinger, 1998; Wallenburg, 2009). Tổng hợp các tài liệu về marketing, vận hành và chuỗi cung ứng dẫn đến giả thuyết tiếp theo về mối quan hệ của lòng tin, cam kết và quan hệ hợp tác kinh doanh lâu dài.

H4a: Kết quả quan hệ có mối liên hệ tích cực với lòng tin của nhà bán lẻ đối với nhà cung cấp của họ

H4b: Kết quả quan hệ có sụ liên kết chặt chẽ với cam kết của nhà bán lẻ đối với nhà cung cấp của họ

H5: Có mối liên hệ nhân quả tích cực giữa lòng tin của nhà bán lẻ đối với nhà cung cấp và cam kết với nhà cung cấp của ho

H6a: Có mối liên hệ nhân quả tích cực giữa lòng tin của nhà bán lẻ đối với nhà cung cấp của ho và mối quan hệ kinh doanh lâu dài

H6b: Có mối liên hệ nhân quả tích cực giữa cam kết của nhà bán lẻ đối với nhà cung cấp của ho và mối quan hệ kinh doanh lâu dài

Chúng tôi kiểm tra giả thuyết bằng cách sử dụng dữ liệu thu từ các siêu thị trên địa bàn Thành phố Hồ Chí Minh. Thiết kế mô hình phương trình cấu trúc được áp dụng để phân tích dữ liệu và rút ra kết luận. 


\section{Phương pháp nghiên cứu}

Nghiên cứu này là một phân tích thăm dò. Công cụ nghiên cứu cho nghiên cứu này là một bảng câu hỏi được thiết kế để thu thập dữ liệu về lợi ích quan hệ, kết quả quan hệ, sự tin tưởng, cam kết và mối quan hệ kinh doanh lâu dài được các nhà bán lẻ cảm nhận. Công cụ nghiên cứu cho mỗi phép đo trong mô hình được tiến hành thông qua quy trình hai bước.

Bước một, tiến hành nghiên cứu tài liệu rộng rãi trong lĩnh vực bán lẻ, tiếp thị và quản lý chuỗi cung ứng, tập trung vào các lợi ích quan hệ, lòng tin, cam kết của khách hàng và mối quan hệ kinh doanh lâu dài trong quản lý chuỗi cung ứng.

Bước hai, tiến hành phỏng vấn với cả hai bên là nhà bán lẻ và các nhà cung cấp, họ là các chuyên gia, nhà quản lý doanh nghiệp, phụ trách kinh doanh của các công ty chủ chốt trong lĩnh vực bán lẻ. Qui mô mẫu được tuyển chọn là 10 ứng viên với bề dày kinh nghiệm từ 10 năm công tác trở lên. Các bản ghi cuộc hội thoại đã được đọc và phân tích cẩn thận, với các cụm từ chính được đánh dấu. Mục tiêu của việc nghiên cứu nội dung các cuộc phỏng vấn là hiểu và xác định suy nghĩ thực sự của người trả lời về lợi ích quan hệ, lòng tin, cam kết và mối quan hệ kinh doanh lâu dài. Thông qua việc nghiên cứu kỹ ý nghĩa của các cuộc phỏng vấn, có thể hiểu biết sơ bộ về các lợi ích quan hệ, các kết quả quan hệ, lòng tin và cam kết của các nhà bán lẻ. Dựa trên các đóng góp của tài liệu đã công bố và quan điểm của các nhà quản lý kinh doanh, các phép đo đã được phát triển và điều chỉnh theo những gợi ý của người tham gia về các khái niệm, từ ngữ và các phép đo. Kết quả nghiên cứu sơ bộ sẽ là cơ sở cho việc thiết kế bảng câu hỏi cho nghiên cứu chính thức.

Khía cạnh khái niệm về lợi ích kinh tế dựa trên các bài viết trước được hiểu là lợi ích tiền tệ. Các thang điểm khảo sát được điều chỉnh theo các thông số chi phí thực tế do ngành bán lẻ áp dụng (tên của công ty không được tiết lộ ở đây để bảo vệ quyền riêng tư). Thang đo lợi ích giá trị gia tăng được điều chỉnh dựa trên thang đo đã công bố (Palaima \& Auruskeviciene, 2007; Qureshi et al., 2007) để phù hợp trong mối quan hệ lợi ích giữa nhà bán lẻ và các nhà cung cấp. Thang đo lợi ích hợp tác sử dụng dựa trên nghiên cứu đã công bố (Benton \& Maloni, 2005; Mohr et al., 1996; Prahinski et al., 2004).

Trong nghiên cứu này, kết quả quan hệ đã được điều chỉnh từ các tài liệu đã công bố trong khu vực quản lý hoạt động (Liu, Luo, \& Liu, 2009). Các nhà bán lẻ tin tưởng và cam kết là trung gian của kết quả quan hệ và mối quan hệ kinh doanh lâu dài (Liu et al., 2009). Kết quả quan hệ, lòng tin, cam kết được rút ra từ một loạt các bài viết (Liu et al., 2009; Morgan \& Hunt, 1994; Sargeant et al., 2006; Wallenburg, 2009). Các thang đo này được kiểm tra và điều chỉnh hợp lý để sử dụng làm thang đo về lòng tin, cam kết và mối quan hệ kinh doanh lâu dài. Thang đo dùng để đo lường các lợi ích liên quan, các kết quả quan hệ, lòng tin/cam kết và mối quan hệ kinh doanh lâu dài được trình bày trong Bảng 1 .

Việc kiểm định các thang đo, mô hình và các giả thuyết đề ra được thực hiện theo các bước: kiểm định sơ bộ bằng hệ số tin cậy Cronbach's Alpha, phân tích nhân tố khẳng định CFA để kiểm định (độ tin cậy tổng hợp, tính đơn nguyên, giá trị hội tụ, và giá trị phân biệt). Mô hình được kiểm định bằng mô hình cấu trúc tuyến tính (SEM). 


\section{Kết quả}

\subsection{Thống kê mô tả}

Cuộc khảo sát cho nghiên cứu chính thức đã được thực hiện trong khoảng thời gian từ ngày 30/12/2017 đến 15/3/2018. Đối tượng tham gia trả lời khảo sát là các nhân viên và người quản lý đang làm việc ở bộ phận kinh doanh tại các siêu thị trên địa bàn TP.HCM. Người tham gia trả lời phỏng vấn được bảo mật thông tin cá nhân và không có bất cứ ảnh hưởng nào đến hoạt động kinh doanh của siêu thị.

Kết quả cụ thể: Tổng số phiếu khảo sát phát ra 450 phiếu, số lượng phiếu thu về là 350 . Trong quá trình nhập và xử lý dữ liệu có 22 phiếu lỗi. Những phiếu lỗi chủ yếu là không trả lời hết những câu hỏi trong Bảng câu hỏi, hoặc trả lời tất cả các tham số như nhau. Kết quả có 328 phiếu khảo sát hợp lệ cấu thành mẫu cho chương trình nghiên cứu chính thức này.

\section{Bảng 1}

Các câu hỏi khảo sát và biến số thống kê mô tả

\begin{tabular}{|c|c|c|c|c|}
\hline $\begin{array}{l}\text { Khái } \\
\text { niệm }\end{array}$ & Ký hiệu & Biến quan sát & $\begin{array}{l}\text { Trung } \\
\text { bình } \\
\text { (Mean) }\end{array}$ & $\begin{array}{l}\text { Độ lệch } \\
\text { chuẩn } \\
\text { (SD) }\end{array}$ \\
\hline \multirow[t]{4}{*}{$\begin{array}{l}\text { Lọi ích } \\
\text { giá trị } \\
\text { gia tăng }\end{array}$} & VAL 1 & $\begin{array}{l}\text { NCC hiểu được nhu cầu hàng hóa của công ty } \\
\text { chúng tôi và đưa ra khuyến nghị theo lịch sử } \\
\text { mua hàng của chúng tôi }\end{array}$ & 3.78 & 0.80 \\
\hline & VAL 2 & $\begin{array}{l}\text { NCC cung cấp thông tin về các quy tắc an toàn } \\
\text { sản phẩm và tuân thủ }\end{array}$ & 3.65 & 0.82 \\
\hline & VAL 3 & $\begin{array}{l}\text { NCC cung cấp các dịch vụ trước khi bán hàng } \\
\text { như mẫu dùng thử, ký gửi hoặc tặng }\end{array}$ & 3.70 & 0.85 \\
\hline & VAL 4 & $\begin{array}{l}\text { NCC có những đề xuất mới và sáng tạo để giúp } \\
\text { cải thiện hoạt động }\end{array}$ & 3.75 & 0.85 \\
\hline \multirow[t]{4}{*}{$\begin{array}{l}\text { Lọi ích } \\
\text { hợp tác }\end{array}$} & COL 1 & $\begin{array}{l}\text { NCC luôn xử lý kịp thời trước những ý kiến } \\
\text { phán ảnh của chúng tôi }\end{array}$ & 3.22 & 0.89 \\
\hline & COL 2 & $\begin{array}{l}\text { Chúng tôi liên lạc thường xuyên với nhau, luôn } \\
\text { thông báo cho nhau trở ngại và hỗ trợ giải quyết } \\
\text { những trường hợp đó }\end{array}$ & 3.21 & 0.90 \\
\hline & COL 3 & $\begin{array}{l}\text { NCC tham gia vào việc lập kế hoạch hợp tác với } \\
\text { chúng tôi }\end{array}$ & 3.19 & 0.93 \\
\hline & COL 4 & $\begin{array}{l}\text { NCC cùng giải quyết các vấn đề kinh doanh với } \\
\text { chúng tôi thông qua các cuộc tư vấn }\end{array}$ & 3.37 & 0.94 \\
\hline $\begin{array}{l}\text { Lọi ích } \\
\text { kinh tế }\end{array}$ & ECON 1 & $\begin{array}{l}\text { NCC có hô̂ trợ đổi trả hàng và giải hàng tồn khi } \\
\text { xảy ra }\end{array}$ & 2.65 & 0.94 \\
\hline
\end{tabular}




\begin{tabular}{lllcc}
\hline $\begin{array}{l}\text { Khái } \\
\text { niệm }\end{array}$ & Ký hiệu & Biến quan sát & $\begin{array}{l}\text { Trung } \\
\text { bình } \\
\text { (Mean) }\end{array}$ & $\begin{array}{l}\text { Độ } \\
\text { chuận } \\
\text { (SD) }\end{array}$ \\
\hline & ECON 2 & NCC chào giá cả cạnh tranh & 3.24 & 0.94 \\
& ECON 3 & NCC cho thời hạn thanh toán thuận lợi & 2.52 & 0.97 \\
& ECON 4 & NCC có chương trình giảm giá hấp dẫn & 2.66 & 1.02
\end{tabular}

Kết quả OTC 1 NCC đã giúp chúng tôi vượt qua các giai đoạn quan hệ kinh doanh khó khăn

$2.42 \quad 0.92$

OTC 2 Chi phí mua hàng giảm, doanh thu kinh doanh của chúng tôi tăng

OTC 3 Quan hệ của chúng tôi với NCC đã mang lại cho chúng tôi lợi thế cạnh tranh trên thị trường về giá và lợi nhuận

OTC 4 Chính sách kinh doanh của NCC giúp chúng tôi đạt chỉ tiêu kinh doanh

OTC 5 NCC giao hàng đúng giờ, đủ số lượng, sản phẩm đạt chất lượng cao, ... cho phép chúng tôi phục vụ khách hàng tốt hơn.

Lòng tin TR 1 Chúng tôi tin tưởng NCC sẽ cung cấp sản phẩm tốt nhất vì lợi ích của công ty chúng tôi

TR 2 Mặc dù thị trường thay đổi, chúng tôi tin tưởng rằng NCC sẽ sẵn sàng giúp đỡ và hỗ trợ chúng tôi

TR 3 Chúng tôi tin tưởng NCC xem rủi ro cũng như cơ hội của chúng tôi cũng như là của chính họ

TR 4 Chúng tôi tin rằng quyết định kinh doanh trong tương lai của NCC sẽ không ảnh hưởng xấu đến chúng tôi

Cam kết COM 1 Chúng tôi cam kết tăng cường mối quan hệ với $\mathrm{NCC}$

COM 2 Công ty chúng tôi đã phát triển mối quan hệ chặt chẽ với công ty XX 


\begin{tabular}{|c|c|c|c|c|}
\hline $\begin{array}{l}\text { Khái } \\
\text { niệm }\end{array}$ & Ký hiệu & Biến quan sát & $\begin{array}{l}\text { Trung } \\
\text { bình } \\
\text { (Mean) }\end{array}$ & $\begin{array}{l}\text { Độ lệch } \\
\text { chuẩn } \\
\text { (SD) }\end{array}$ \\
\hline \multirow{6}{*}{$\begin{array}{l}\text { Mối } \\
\text { quan hệ } \\
\text { hợp tác } \\
\text { lâu dài }\end{array}$} & COM 3 & $\begin{array}{l}\text { Trong số tất cả các nhà cung cấp của chúng tôi, } \\
\text { duy trì quan hệ kinh doanh với NCC này là quan } \\
\text { trọng nhất }\end{array}$ & 3.95 & 0.77 \\
\hline & $\mathrm{COM} 4$ & $\begin{array}{l}\text { Công ty chúng tôi cam kết cho NCC này nhiều } \\
\text { hơn là các NCC khác }\end{array}$ & 4.00 & 0.77 \\
\hline & LTR 1 & $\begin{array}{l}\text { XX đã là nhà cung cấp chính của công ty chúng } \\
\text { tôi trong nhiều năm qua }\end{array}$ & 3.06 & 1.35 \\
\hline & LTR 2 & $\begin{array}{l}\text { Công ty chúng tôi sẽ tiếp tục kinh doanh với } \\
\text { NCC này }\end{array}$ & 3.84 & 0.77 \\
\hline & LTR 3 & $\begin{array}{l}\text { Công ty chúng tôi mong muốn NCC này sẽ là } \\
\text { nhà cung cấp chiến lược của công ty }\end{array}$ & 3.84 & 0.78 \\
\hline & LTR 4 & $\begin{array}{l}\text { Công ty chúng tôi có kế hoạch duy trì mối quan } \\
\text { hệ với NCC này }\end{array}$ & 3.74 & 0.80 \\
\hline
\end{tabular}

*Thang đo Likert 5 mức độ cho tất cả các câu hỏi điều tra là:1= hoàn toàn không đồng ý đến 5 = hoàn toàn đồng ý

Nguồn: Kết quả phân tích dữ liệu của nhóm nghiên cứu

\subsection{Kết quả đánh giá độ tin cậy, giá trị hội tụ, giá trị phân biệt}

Kết quả cuộc điều tra sơ bộ được thể hiện dưới đây với phần kiểm định thang đo cho từng biến tổng hợp. Kết quả đánh giá độ tin cậy của thang đo bằng hệ số Cronbach's Alpha và hệ số tương quan biến tổng cho thấy tương quan biến tổng của tất cả các biến quan sát đều lớn hơn 0.3 và hệ số Cronbach's Alpha lần lượt của thang đo Lợi ích giá trị gia tăng, Lợi ích hợp tác, Lợi ích kinh tế, Kết quả quan hệ, Lòng tin và Cam kết có $\alpha=0.913 ; 0.900 ; 0.793 ; 0.941$; $0.859 ; 0.935>0.6$. Riêng, thang đo Mối quan hệ hợp tác lâu dài được cấu thành bởi bốn biến quan sát. Kết quả phân tích độ tin cậy của thang đo ban đầu cho thấy hệ số $\alpha=0.589<0.6$, thang đo không đảm bảo độ tin cậy cần thiết. Biến LTR1 "XX đã là nhà cung cấp chính của công ty chúng tôi trong nhiều năm qua", có hệ số tương quan biến tổng là $(0.027)<0.3$ và nếu loại đi sẽ làm tăng độ tin cậy của thang đo, do đó loại biến này. Sau khi loại biến LTR1, tính toán lại độ tin cậy của thang đo, có $\alpha=0.938$ và tương quan biến tổng của tất cả các biến trong thang đo này biến thiên từ 0.866 đến 0.875 đều $>0.3$. Như vậy thang đo đáp ứng độ tin cậy cần thiết.

Kết quả phân tích nhân tố CFA cho thấy chỉ số Chi-square $=450.215$; CMINldf=1.368; $\mathrm{TLI}=0.979 \mathrm{GFI}=0.913 ; \mathrm{CFI}=0.918$ và $\mathrm{RMSEM}=0.034$. Các chỉ số điều thỏa mãn điều kiện phù hợp với mô hình, do đó có thể kết luận rằng mô hình đo lường phù hợp với dữ liệu thị trường. 
Ngoài ra, khi quan sát các hệ số chuẩn hóa đều lớn hơn 0.5 và có mức ý nghĩa thống kê $(\mathrm{p}=0.000)$. Điều này thể hiện được tính hội tụ của mô hình và cấu trúc dữ liệu là phù hợp cho việc phân tích.

Giá trị $\mathrm{P}$-value đều < 0.05 nên hệ số tương quan của từng cặp khái niệm khác biệt so với 1 ở độ tin cậy 95\%. Do đó, các khái niệm đạt được giá trị phân biệt.

Tóm lại, mỗi khái niệm có thang đo với độ tin cậy thỏa đáng, đạt giá trị hội tụ và giá trị phân biệt; tất cả các kích thước của khái niệm được hỗ trợ bởi kết quả phân tích nhân tố và sự phù hợp của mô hình kết hợp tất cả các chỉ số này là phù hợp với các tiêu chuẩn được chấp nhận trong tài liệu đã đề xuất (Bentler, 1990).

\subsection{Mô hình cấu trúc tuyến tính SEM}

Trong phần này, mô hình cấu trúc tuyến tính SEM được thực hiện để kiểm tra các giả thuyết được đề xuất trong mô hình nghiên cứu. Kết quả thực hiện mô hình cấu trúc tuyến tính SEM cho ra các chỉ tiêu có giá trị như sau: ${ }^{2} / \mathrm{df}=1.546(<2)$ đạt yêu cầu cho độ tương thích, đồng thời các chỉ tiêu khác cũng đạt yêu cầu: $\mathrm{CFI}=0.971, \mathrm{GFI}=0.900, \mathrm{TLI}=0.968(\geq 0.9)$ và RMSEA = $0.041(<0.05)$. Các chỉ số này đều đáp ứng được các yêu cầu về mặt lý thuyết (Hair và cộng sự, 1998). Vì vậy, có thể kết luận mô hình cấu trúc tuyến tính SEM này thích hợp với dữ liệu thu thập từ thị trường.

\section{Bảng 2}

Kết quả kiểm định mô hình cấu trúc tuyến tính SEM

\section{Paths}

\section{Standard path coefficient}

\begin{tabular}{llc}
\hline H1 & Lợi ích giá trị gia tăng $\rightarrow$ Kết quả quan hệ & $\gamma_{1}=0.176$ \\
H2 & Lợi ích hợp tác $\rightarrow$ Kết quả quan hệ & $\gamma_{2}=0.243$ \\
H3 & Lợi ích kinh tế $\rightarrow$ Kết quả quan hệ & $\gamma_{3}=0.277$ \\
H4a & Kết quả quan hệ $\rightarrow$ Lòng tin & $\beta_{1}=0.332$ \\
H4b & Kết quả quan hệ $\rightarrow$ Cam kết & $\beta_{2}=0.143$ \\
H5 & Lòng tin $\rightarrow$ Cam kết & $\beta_{3}=0.272$ \\
H6a & Cam kết $\rightarrow$ Hợp tác lâu dài & $\beta_{4}=0.576$ \\
H6b & Lòng tin $\rightarrow$ Hợp tác lâu dài & $\beta_{5}=0.126$ \\
Squared multiple correlations & $\mathbf{R}^{\mathbf{2}}$ \\
\hline \multicolumn{3}{c}{ F4 Nhân tố kết quả mối quan hệ } \\
$\quad$ F5 Nhân tố lòng tin & 0.167 \\
$\quad$ F6 Nhân tố cam kết & 0.110 \\
F7 Nhân tố hợp tác lâu dài & 0.120 \\
Model fit indices & 0.394 \\
\hline Chi-square $\left(\chi^{2}\right)$ & \\
\hline$f f$ & 528.655
\end{tabular}


Paths

Standard path coefficient

\begin{tabular}{ll}
\hline Chi-square/df & 1.546 \\
RMSEA & 0.041 \\
CFI & 0.971 \\
GFI & 0.900 \\
TLI & 0.968 \\
\hline
\end{tabular}

Nguồn: Kết quả xử lý từ dữ liệu điều tra

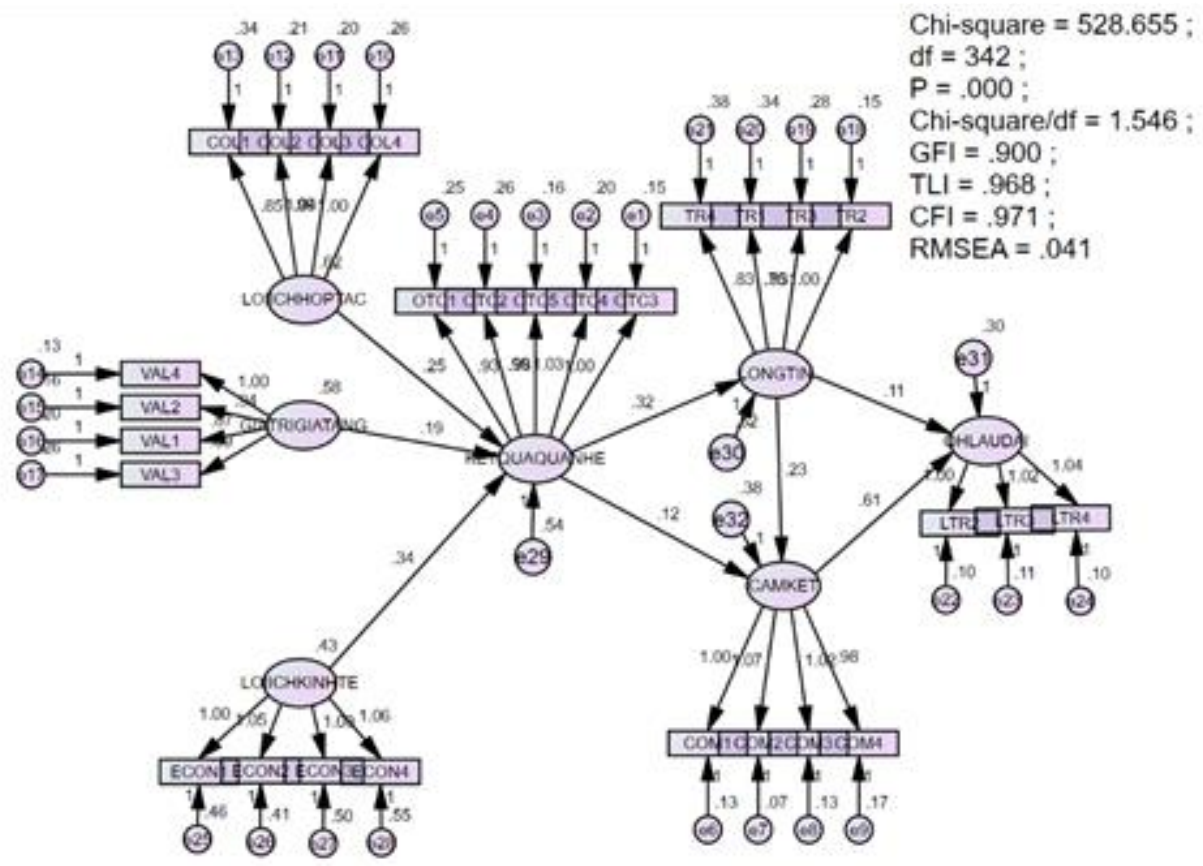

Hình 2. Mô hình cấu trúc tuyến tính SEM

Nguồn: Kết quả xử lý từ phần mềm AMOS 22

Sau khi xác định mô hình là thích hợp với dữ liệu thu thập từ thị trường, các trọng số có ý nghĩa thống kê nên các khái niệm đạt được giá trị hội tụ, giá trị phân biệt. Từ Bảng 2, cho thấy:

Các lợi ích mối quan hệ (lợi ích giá trị gia tăng, lợi ích hợp tác, và lợi ích kinh tế) được giả định là có tác động dương đến các kết quả mối quan hệ (H1, H2 và $\mathrm{H} 3)$. Giả thiết này được chấp nhận với giá trị $\mathrm{p}<0.05$, có ý nghĩa thống kê $(\gamma 1=0.176, p<0.05 ; \gamma 2=0.243, p<0.05$ và $\gamma 3=0.277, p<0.05)$.

H4a và $\mathrm{H} 4 \mathrm{~b}$ đã kiểm tra tác động của kết quả quan hệ trên sự tin tưởng và cam kết của nhà bán lẻ. Trọng số chuẩn hóa cho H4a được tìm thấy có ý nghĩa ở mức $1=0.332(p<0.05)$. Kết quả cho thấy có mối liên hệ nhân quả tích cực giữa kết quả mối quan hệ và lòng tin. Tuy nhiên, sự liên quan giữa kết quả mối quan hệ và cam kết $(\mathrm{H} 4 \mathrm{~b})$, mặc dù là tác động dương, nhưng trọng số chuẩn hóa thấp $2=0.143$. Kết quả này phù hợp với quan điểm về lòng tin và cam kết của khách hàng (Sargeant et al., 2006). 
H5 đã kiểm tra mối quan hệ nhân quả giữa niềm tin và cam kết. Trọng số chuẩn hóa cho H5 đã được tìm thấy có ý nghĩa ở mức $3=0.272(p<0.05)$. Cuối cùng, điều này đã được khẳng định rằng cam kết (H6a) và sự tin tưởng $(\mathrm{H} 6 \mathrm{~b})$ sẽ có một mối quan hệ nhân quả rõ ràng với mối quan hệ kinh doanh lâu dài giữa các nhà bán lẻ và nhà cung cấp. Mối quan hệ giữa cam kết và mối quan hệ lâu dài (H6a) là tích cực và có ý nghĩa $4=0.576(p<0.05)$. Mối quan hệ giữa niềm tin và mối quan hệ lâu dài, tác động dương, nhưng cũng khá thấp.

Hay nói cách khác, các giả thiết sau đây đều được chấp nhận:

H1: Lợi ích giá trị gia tăng ảnh hương tích cực đến kết quả quan hệ

H2: Các lợi ích cộng tác ảnh hương tích cực đến kết quả quan hệ

H3: Lợi ích kinh tế tích cực ảnh hưởng đến kết quả quan hệ

H4a: Kết quả quan hệ có mối liên hệ tích cực với lòng tin của nhà bán lẻ đối với nhà cung cấp của ho

H4b: Kết quả quan hệ có sụ liên kết chặt chẽ với cam kết của nhà bán lẻ đối với nhà cung cấp của họ

H5: Có mối liên hệ nhân quả tích cực giữa lòng tin của nhà bán lẻ đối với nhà cung cấp và cam kết với nhà cung cấp của ho

H6a: Có mối liên hệ nhân quả tích cực giữa lòng tin của nhà bán lẻ đối với nhà cung cấp của ho và mối quan hệ kinh doanh lâu dài

H6b: Có mối liên hệ nhân quả tích cực giũa cam kết của nhà bán lẻ đối với nhà cung cấp của ho và mối quan hệ kinh doanh lâu dài

\section{Thảo luận và kiến nghị}

\section{lâu dài \\ 5.1. Tác động tích cụ̂c của lòng tin và cam kết tạo ra mối quan hệ hợp tác kinh doanh}

Bài nghiên cứu này xác nhận rằng các lợi ích mối quan hệ trong môi trường dịch vụ mà nhà cung cấp mang lại cho nhà bán lẻ sẽ ảnh hưởng đến kết quả mối quan hệ giữa cả hai bên; trung gian qua sự tin tưởng và cam kết, kết quả của lợi ích mối quan hệ sẽ ảnh hưởng đến mối quan hệ kinh doanh lâu dài.

Mục tiêu chính của quản lý mối quan hệ chuỗi cung ứng là xác định tác nhân chính ảnh hưởng đến kết quả quan trọng cho công ty và hiểu rõ hơn về mối quan hệ nhân quả giữa các tác nhân và kết quả thực hiện của công ty. Kết quả của nghiên cứu này cho thấy các lợi ích mối quan hệ có thể giúp giải thích một số lượng đáng kể sự thành công của mối quan hệ giữa các nhà bán lẻ và các nhà cung cấp hàng hóa của họ. Hơn nữa, nghiên cứu cung cấp một số hiểu biết ban đầu về làm thế nào để biến đổi một nhà cung cấp từ một nhà cung cấp cơ bản trở thành một đối tác chiến lược dài hạn của nhà bán lẻ. Phân tích cũng chỉ ra rằng các nhà cung cấp cần tích cực xây dựng và cung cấp các hoạt động dịch vụ thông qua các giá trị lợi ích từ đó thúc đẩy tạo ra lòng tin và cam kết, điều này có thể giúp tạo ra các kết quả quan trọng ở phía khách hàng của họ. Chuyển đổi lợi ích các quan hệ sang các kết quả quan hệ thỏa đáng tạo niềm tin 
từ các nhà bán lẻ, những người lần lượt sẽ cam kết với mối quan hệ kinh doanh lâu dài với các nhà cung cấp.

Trong khi giả thuyết H6b có tác động mạnh tích cực, thì giả thuyết H6a ít tác động hơn. Sự tin cậy chắc chắn là quan trọng trong mối quan hệ chuỗi cung ứng và sự tin tưởng giữa các tổ chức đã được lập luận là có những hệ quả tích cực cho sự thành công của một mối quan hệ (Tatham \& Kovács, 2010). Tuy nhiên, sự tin cậy duy nhất sẽ không đủ để duy trì mối quan hệ kinh doanh lâu dài. Kết quả của chúng tôi chỉ ra rằng sự tin tưởng giữa các nhà bán lẻ và nhà cung cấp của họ cần phải được hỗ trợ bởi cam kết để thiết lập mối quan hệ lâu dài. Không có gì đáng ngạc nhiên, trong quản lý chuỗi cung ứng (Benton \& Maloni, 2005; Sargeant et al., 2006) đều dựa trên sự tin tưởng như một yếu tố thành công quan trọng cho sự cam kết, mặc dù phần lớn kết quả là tạo mối quan hệ lâu dài. Điều này phù hợp với sự khẳng định của Benton và Maloni (2005) tin tưởng đó có ảnh hưởng tích cực đến cam kết và sự hài lòng của đối tác chuỗi cung ứng là do bản chất của mối quan hệ. Từ kết quả của nghiên cứu này, chúng ta có thể kết luận rằng sự tin tưởng là một trạng thái của tâm trí và cam kết là một hành động. Khi sự tin tưởng được chuyển thành cam kết, hành động này được coi là một tín hiệu trực tiếp rằng nhà cung cấp có thể được tin cậy. Cần lưu ý rằng có một ảnh hưởng của kết quả mối quan hệ về cam kết - thông qua sự tin tưởng - như vậy khi mà các nhà bán lẻ đạt được những kết quả mong muốn thông qua các lợi ích do nhà cung cấp cung cấp, kết quả tích cực sẽ ảnh hưởng đến lòng tin, và điều đó sẽ tác động tích cực đến sự cam kết và lâu dài quan hệ kinh doanh.

Nói tóm lại, tạo ra các mối quan hệ kinh doanh lâu dài và cạnh tranh trên thị trường đòi hỏi các đối tác trong chuỗi cung ứng phải là hợp tác kinh doanh đáng tin cậy.

\subsection{Lợi ích mối quan hệ là tác động chính đến lòng tin/cam kết và tạo ra quan hệ đối tác chiến lược lâu dài}

Các yếu tố tác động chính ảnh hưởng đến lòng tin/cam kết và tạo ra quan hệ đối tác chiến lược lâu dài là những lợi ích quan trọng. Lợi ích quan trọng tập trung vào những lợi ích mà các nhà sản xuất nhận được ngoài dịch vụ cốt lõi, tập trung vào bản chất tổng thể của mối quan hệ và sự hiểu biết về mối quan hệ kinh doanh lâu dài. Quan điểm về lợi ích quan hệ cho thấy kết quả quan hệ và sự tin tưởng/cam kết là trung tâm của chất lượng mối quan hệ chuỗi cung ứng. Khi nhà cung cấp có thể hỗ trợ kinh doanh cho khách hàng bằng cách cung cấp các lợi ích giá trị gia tăng, lợi ích hợp tác và lợi ích kinh tế, khách hàng của họ sẽ xem mối quan hệ của họ là mối quan hệ chung và sẵn sàng cam kết duy trì mối quan hệ chiến lược dài hạn. Lợi ích hợp tác đã được tìm thấy là rất quan trọng trong việc tăng cường kết quả quan hệ của nhà bán lẻ. Hợp tác truyền thông có thể giúp thiết lập một bầu không khí hỗ trợ lẫn nhau, qua đó tạo ra sự gắn bó tốt hơn giữa các nhà bán lẻ và nhà cung cấp của họ. Dựa trên số liệu điều tra, những phát hiện gợi ý rằng khi mức độ hợp tác cao, hiệu quả của các lợi ích hợp tác đối với kết quả quan hệ thì tốt hơn so với sự cộng tác thấp. Truyền thông hợp tác, lập kế hoạch hợp tác và giải quyết vấn đề là rất quan trọng để duy trì mối quan hệ trung thành và làm cho cả hai nhà bán lẻ và nhà cung cấp cảm thấy như một phần không thể tách rời của một nhóm để phấn đấu cho cùng một mục tiêu. Bằng việc bồi dưỡng các giá trị chia sẻ và hỗ trợ lẫn nhau, và sắp xếp lại quá trình kinh doanh, lợi ích hợp tác mang lại cho nhà sản xuất thêm động lực để tạo mối quan hệ lâu dài với các nhà cung cấp. 
Quản lý mối quan hệ với các đối tác trong chuỗi cung ứng không chỉ đòi hỏi sự hiểu biết về tác động của các lợi ích quan hệ được nhận biết đối với kết quả quan hệ và mối quan hệ kinh doanh lâu dài mà còn là kiến thức đầy đủ về cách đánh giá và duy trì mối quan hệ với các nhà cung cấp bên ngoài. Với nhà bán lẻ, những người đã được hưởng lợi từ giá cả cạnh tranh, dịch vụ giá trị gia tăng và cam kết của nhà cung cấp, cần thiết phải tạo ra một liên kết chặt chẽ với nhà cung cấp và đầu tư vào mối quan hệ liên tục.

Khi được áp dụng chính xác, mô hình lợi ích quan hệ được gợi ý trong nghiên cứu này có thể giúp chuyển đổi một nhà cung cấp mới thành một đối tác chiến lược lâu dài có thể giúp tăng cường lợi thế cạnh tranh trong chuỗi cung ứng tổng thể của công ty. Bằng cách làm nổi bật lợi ích chung và các mục tiêu chung, các lợi ích liên quan có thể tạo ra sự tuân thủ dự kiến giữa các đối tác kinh doanh và tăng kết quả chuỗi cung ứng tích cực.

\subsection{Kiến nghị}

Trong nghiên cứu này, phần nào đã phát triển một mô hình khái niệm, thêm vào những hiểu biết lý thuyết mới về các bộ ba lợi ích - kết quả - lòng trung thành đã được áp dụng bởi các nhà bán lẻ và nhà cung cấp và cung cấp một số quan điểm có ý nghĩa về cách đánh giá việc phối hợp các nhà cung cấp, làm sao chuyển đổi từ một nhà cung cấp chiến thuật thành một đối tác kinh doanh dài hạn. Sự đóng góp của nghiên cứu này là cung cấp một số ý tưởng có liên quan để giúp các nhà bán lẻ tạo ra sự hợp tác có ý nghĩa với nhà cung cấp của họ về các vấn đề chiến lược. Bài nghiên cứu đã miêu tả hoạt động dịch vụ cung cấp hàng hóa của nhà cung cấp dưới mắt nhìn từ các nhà bán lẻ. Cụ thể, nghiên cứu đánh giá lợi ích dịch vụ của nhà cung cấp và kết quả quan hệ bằng cách sử dụng tiếng nói của khách hàng hơn là dựa vào xếp hạng báo cáo của nhà cung cấp. Có một số hạn chế cần được xem xét để nghiên cứu trong tương lai. Thứ nhất, ngày càng có nhiều nhà bán lẻ tự sản xuất và trở thành nhà cung cấp cho chính họ. Nghiên cứu này có thể là điểm khởi đầu cho các nhà bán lẻ để phân tích quá trình kinh doanh của họ trước khi xem xét việc tự cung tự cấp hàng hóa không qua nhà cung cấp bên ngoài. Trong nghiên cứu này đã không chia các nhà cung cấp theo từng nhóm hàng hóa riêng mà các nhà bán lẻ mua. Nên nghiên cứu trong tương lai có thể khám phá các lợi ích liên quan dựa trên các loại hình dịch vụ cung cấp hàng hóa khác nhau.

Thứ hai, phân tích thống kê của bài nghiên cứu dựa trên dữ liệu thu thập được từ các nhà bán lẻ, mặc dù nghiên cứu đã tiến hành các cuộc phỏng vấn cá nhân với các nhà cung cấp. Nghiên cứu trong tương lai có thể xem xét cả hai nhà sản xuất và các nhà cung cấp cùng một lúc để cả hai bên có thể hiểu được lợi ích và sự đánh giá dành cho nhau.

Thứ ba, có một số câu hỏi nghiên cứu liên quan đến chuỗi cung ứng và các mối quan hệ từ nghiên cứu này đáng để nghiên cứu thêm: (1) Trường hợp hợp tác tốt và cạnh tranh tốt là gì? (2) Loại hợp tác nào là tốt nhất ở giai đoạn đầu hợp tác và mức độ hợp tác nào là tốt nhất với đối tác thuê ngoài? (3) Có phải hợp tác yếu sẽ tạo thuận lợi cho việc thăm dò và hợp tác mạnh mẽ tạo điều kiện thuận lợi cho việc khai thác? (4) Khi nào các doanh nghiệp tạo sức ép khó khăn trong thương lượng và khi nào họ nên tham gia vào thỏa hiệp vì lợi ích lẫn nhau khi các doanh nghiệp muốn gây dựng mối quan hệ với các công ty khác? Cuối cùng, đề nghị nghiên cứu trong tương lai tìm hiểu mối quan hệ giữa các chiến lược quan hệ và ba lợi ích quan hệ 
được xác định trong nghiên cứu này. Chiến lược này nên tăng cường mối quan hệ tích cực giữa các đối tác trong chuỗi cung ứng.

\section{Tài liệu tham khảo}

Abreu, M., Grinevich, V., Hughes, A., Kitson, M., \& Ternouth, P. (2008). Universities, business and knowledge exchange. Retrieved May 25, 2017, from https://www.cbr.cam.ac.uk/fileadmin/user_upload/centre-for-business-

research/downloads/special-reports/specialreportuniversitiesbusinessknowledgeexchange.pdf

Anderson, J. C., \& Narus, J. A. (1990). A model of distributor firm and manufacturer firm working partnerships. Journal of Marketing, 54(1), 42-58.

Bendapudi, N., \& Berry, L. L. (1997). Customers' motivations for maintaining relationships with service providers. Journal of Retailing, 73(1), 15-37.

Benton, W. C., \& Maloni, M. (2005). The influence of power driven buyer/seller relationships on supply chain satisfaction. Journal of Operations Management, 23(1), 1-22.

Berry, L. L. (1995) Relationship marketing of services: Growing interest, emerging perspectives. Journal of the Academy of Marketing Science, 23(4), 236-245. doi:10.1177/009207039502300402

Bruning, M. K. (2019). Collaborative recovery from supply chain disruptions. In C. Bode, R. Bogaschewsky, M. Eßig, R. Lasch, \& W. Stölzle (Eds.), Supply management research. Advanced studies in supply management (pp. 51-75). Gabler, Wiesbaden: Springer.

Cachon, G. P., \& Fisher, M. (2000). Supply chain inventory management and the value of shared information. Management Science, 46(8), 1032-1048

Cannon, J. P., \& Perreault, W. D. (1999). Buyer-seller relationships in business markets. Journal of Marketing Research, 36(4), 439-460

Cao, M., Vonderembse, M. A., Zhang, Q., \& Ragu-Nathan, T. S. (2010). Supply chain collaboration: Conceptualization and instrument development. International Journal of Production Research, 48(22), 6613-6635.

Daniel, C., \& Nirmalya, K. (2005). Do suppliers benefit from collaborative relationships with large retailers? An empirical investigation of efficient consumer response adoption. Journal of Marketing, 69(6), 80-94.

Daugherty, P. J., Stank, T. P., \& Ellinger, A. E. (1998). Leveraging logistics/distribution capabilities: The effect of logistics service on market share. Journal of Business Logistics $19(2), 35-51$.

Davis-Sramek, B., Mentzer, J. T., \& Stank, T. P. (2008). Creating consumer durable retailer customer loyalty through order fulfillment service operations. Journal of Operations Management, 26(6), 781-797.

Do, M. N., \& Dang, M. V. (2008). Quan hệ hợp tác giữa các nhà sản xuất và nhà phân phối trong lĩnh vực hàng tiêu dùng: Nghiên cứu thăm dò [Cooperation between manufacturers 
and distributors in the consumer goods sector: Research and exploration]. Tap chi Khoa học và công nghệ Đại học Đà Nẵng, 3(26), 145-154.

Dwyer, F. R., Schurr, P. H., \& Oh, S. (1987). Developing buyer-seller relationships. Journal of Marketing, 51(5), 11-27.

Fynes, B., de Búrca, S., \& Voss, C. (2005). Supply chain relationship quality, the competitive environment and performance. International Journal of Production Research, 43(16), 3303-3320. doi:10.1080/00207540500095894

Ganesan, S. (1994). Determinants of long-term orientation in buyer-seller relationships. Journal of Marketing, 58(4), 1-19.

Gilbert, N. N., Judith, M. W., \& Daniel, F. L. (2010). Examining supply chain relationships: Do buyer and supplier perspectives on collaborative relationships differ? Journal of Operations Management, 28(2), 101-114.

Grover, V., Teng, J., \& Fiedler, K. (2002). Investigating the role of information technology in building buyer-supplier relationships. Journal of Association for Information Systems, $3(1), 217-450$.

Gwinner, K. P., Gremler, D. D., \& Bitner, M. J. (1998). Relational benefits in services industries: The customer's perspective. Academy of Marketing Science Journal, 26(2), 101-115.

Handfield, R. B. (1993). A resource dependence perspective of just-in-time purchasing. Journal of Operations Management, 11(3), 289-311

Henning-Thurau, T., Gwinner, K. P., \& Gremler, D. D. (2002). Understanding relationship marketing outcomes: An integration of relational benefits and relationship quality. Journal of Service Research, 4(3), 230-470.

Hoang Trong, \& Chu, N. N. M. (2008). Phân tích dũ liệu nghiên cúu với SPSS [Analyze research data with SPSS]. Hanoi, Vietnam: Nhà xuất bản Thống kê.

Hoang, C. L. (2013). Chất lương mối quan hệ giữa nhà cung cấp dịch vu và khách hàng: Nghiên cứu trường hợp khách hàng công nghiệp ngành dịch vu viễn thông [Quality of the relationship between service providers and customers: The telecom service industry customer case study]. (Doctoral dissertation). University of Economics Ho Chi Minh City, Ho Chi Minh, Vietnam.

Hoang, C. L. (2012). Các nhân tố tác động lên lòng tin trong mối quan hệ giữa nhà cung cấp dịch vụ viễn thông và khách hàng doanh nghiệp tại Viêt Nam [Factors influencing trust in the relationship between telecommunications service providers and corporate customers in Vietnam]. Tạp chí Kinh tế và Phát triển, 183, 27-35.

Hoang, C. L. (2013). Rào cản chuyển đổi và lòng trung thành của khách hàng: Vai trò trung gian của sự cam kết [Conversion barriers and customer loyalty: The intermediary role of the commitment]. Tạp chí Kinh tế và Phát triển, 189(II), 96-103.

Hsiao, K.-L., Lin, J. C.-C., Wang, X.-Y., Lu, H.-P., \& Yu, H. (2010). Antecedents and consequences of trust in online product recommendations: An empirical study in social shopping. Online Information Review, 34(6), 935-953. doi:10.1108/14684521011099414 
Hunt, S. D. (1990). Truth in marketing theory and research. Journal of Marketing, 54(3), 1-15.

Johnson, J. L., \& Black, G. S. (1996). The effects of relationalism and supplier replaceability on industrial distribution channel outcomes. Journal of Marketing Channels, 5(2), 25-44.

Johnston, D. A., Mccutcheon, D. M., Stuart, F. I., \& Kerwood, H. (2004). Corrigendum to effects of supplier trust on performance of cooperative supplier relationships. Journal of Operations Management, 22(5), 23-38.

Kumar, N., Scheer, L. K., \& Steenkamp, J.-B. E. M. (1995). The effect of supplier fairness on vulnerable resellers. Journal of Marketing Research, 32(1), 54-65.

Le, N. T. M., \& Nguyen, T. T. M. (2014). Lợi ích mối quan hệ, cam kết, sự thỏa mãn và lòng trung thành: Trường hợp khách hàng cá nhân tại ngân hàng TP.HCM, Việt Nam [Relationship benefits, commitment, satisfaction and loyalty: In the case of an individual customer at a bank in Ho Chi Minh City, Vietnam]. Tạp chí phát triển Khoa học và công nghẹ, Q3, 61-70.

Li, L. (2006). The effects of information technology implementation on supply chain collaboration. International Journal of Internet and Enterprise Management, 4(2), 118134.

Li, L. Y. (2011). Marketing of competence-based solutions to buyers in exploratory relationships: Perspective of OEM suppliers. Industrial Marketing Management, 40(7), 1206-1213.

Li, L., \& Warfield, J. N. (2011). Perspectives on quality coordination and assurance in global supply chains. $\quad$ Retrieved May 20, 2017, from https://digitalcommons.odu.edu/cgi/viewcontent.cgi?article=1021\&context=itds_facpub s

Ling, L., John, B. F., Xin, Z., \& Li, X. (2012). Relational benefits and manufacturer satisfaction: An empirical study of logistics service in supply chain. International Journal of Production Research, 50(19), 5445-5459.

Liu, Y., Luo, Y., \& Liu, T. (2009). Governing buyer-supplier relationships through transactional and relational mechanisms: Evidence from China. Journal of Operations Management, 27(4), 294-309.

Long, T., \& Nelson, A. (2010). Speech, supply chain management in Norfolk Southern Corporation. Norfolk, VI: Norfolk Southern.

Luthra, S., Mangla, S. K., Chan, F. T., \& Venkatesh, V. G. (2018). Evaluating the drivers to information and communication technology for effective sustainability initiatives in supply chains. International Journal of Information Technology \& Decision Making, 17(1), 311-338.

Ma, J., Wang, K., \& Xu, L. (2011). Modelling and analysis of workflow for lean supply chains. Enterprise Information Systems 5(4), 423-447. doi:10.1080/17517575.2011.580007

Mentzer, J. T., Dewitt, W., Keebler, J. S., Min, S., Nix, N. W., Smith, C. D., \& Zacharia, Z. G. (2001). Defining supply chain management. Journal of Business Logistics, 22(2). doi:10.1002/j.2158-1592.2001.tb00001.x 
Mohr, J. J., Fisher, R. J., \& Nevin, J. R. (1996). Collaborative communication in inter-firm relationships: Moderating effects of integration and control. Journal of Marketing, 60(3), 103-115.

Moorman, C., Zaltman, \& Deshpande, R. (1992). Relationships between providers and users of market Research: The dynamics of trust within and between organizations. Journal of Marketing Research, 29, 314-329.

Morgan, R. M., \& Hunt, S. D. (1994). The commitment-trust theory of relationship marketing. Journal of Marketing, 58(3), 20-38.

Morton, S. C., Dainty, A. R. J., Burns, N. D., Brookes, N. J., \& Backhouse, C. J. (2006). Managing relationships to improve performance: A case study in the global aerospace industry. International Journal of Production Research, 44(16), 3227-3241.

Palaima, T., \& Auruskeviciene, V. (2007). Modeling relationship quality in the parcel delivery services market. Baltic Journal of Management, 2(1), 37-54.

Patterson, P. G., \& Smith, T. (2001). Relationship benefits in service industries: A replication in a Southeast Asia context. Journal of Services Marketing, 15(6), 425-443.

Peterson, R. A. (1995). Relationship marketing and the consumer. Journal of the Academy of Marketing Science, 23(4), 278-281.

Pham, L. T. M. (2009). Khả năng cạnh tranh của doanh nghiệp bán lẻ Việt Nam hậu WTO: Vấn đề quản trị chuỗi cung ứng và logistics [Post-WTO Vietnamese retail business competitiveness: Supply chain management and logistics]. Tạp chí Khoa hoc và úng dụng, 10, 14-17.

Prahinski, C., \& Benton, W. C. (2004). Supplier evaluations: Communication strategies to improve supplier performance. Journal of Operations Management, 22(1), 39-62.

Prahinsky, C., \& Benton, Wc (2004). Supplier evaluations: Communication strategies to improve supplier performance. Journal of Operations Management, 22(1), 39-62. doi:10.1016/j.jom.2003.12.005

Qureshi, M. N., Kumar, D., \& Kumar, P. (2007). Modeling the logistics outsourcing relationship variables to enhance shippers' productivity and competitiveness in logistical supply chain. International Journal of Productivity and Performance Management, 56(8), 689-714.

Rafiq, M., \& Jaafar, H. S. (2007). Measuring customers' perceptions of logistics service quality of 3pl service providers. Journal of Business Logistics, 28(2), 159-175.

Raweewan, M., \& Ferrell, W. G., Jr. (2018). Information sharing in supply chain collaboration. Computers \& Industrial Engineering, 126, 269-281.

Rokkan, A. I., Heide, J. B., \& Wathne, K. (2003). Specific investments in marketing relationships: Expropriation and bonding effects. Journal of Marketing Research, 40(2), 210-224. doi:10.1509/jmkr.40.2.210.19223

Sahay, B. S. (2003). Understanding trust in supply chain relationships. Industrial Management and Data Systems, 103(8), 553-563 
Sargeant, A., Ford, J. B., \& West, D. C. (2006). Perceptual determinants of nonprofit giving behavior. Journal of Business Research, 59(2), 155-165. doi:10.1016/j.jbusres.2005.04.006

Sheth, J. N., \& Parvatiyar, A. (1995). Relationship marketing in consumer markets. Journal of the Academy of Marketing Science, 23(4), 255-271. doi:10.1177/009207039502300405

Simatupang, T. M., \& Sridharan, R. (2002). The collaborative supply chain. International Journal of Logistics Management, 13(1), 15-30.

Stank, T. P., Keller, S. B., \& Daugherty, P. J. (2003). Supply chain collaboration and logistical service performance. Journal of Business Logistics, 22(1), 29-48.

Tatham, P., \& Kovács, G. (2010). The application of "swift trust" to humanitarian logistics. International Journal of Production Economics, 126(1), 35-45. doi:10.1016/j.ijpe.2009.10.006

Trentin, G. (2010). Networked collaborative learning: Social interaction and active learning. Newland Park, UK: Chandos Publishing.

Wallenburg, C. M. (2009). Innovation in logistics outsourcing relationships: Proactive improvement by logistics service providers as a driver of customer loyalty. Journal of Supply Chain Management, 45(2), 75-93. doi:10.1111/j.1745-493X.2009.03164.x

$\mathrm{Xu}$, L. (2011a). Information architecture for supply chain quality management. International Journal of Production Research, 49(1), 183-198.

$\mathrm{Xu}, \mathrm{L}$. (2011b). Enterprise systems: State of the art and future trends. IEEE Transactions on Industrial Informatics, 7(4), 630-640.

Zdravkovic, S., Magnusson, P., \& Westjohn, S. A. (2011). Further clarification on how perceived brand origin affects brand attitude: A reply to Samiee and Usunier. International Marketing Review, 28(5), 497-507. doi:10.1108/02651331111167615 